\section{Muntadas. On Media Control}

LUNA, Diego

Universidad de Cádiz, Cádiz, 2018

ISBN: 978-84-9828-713-4

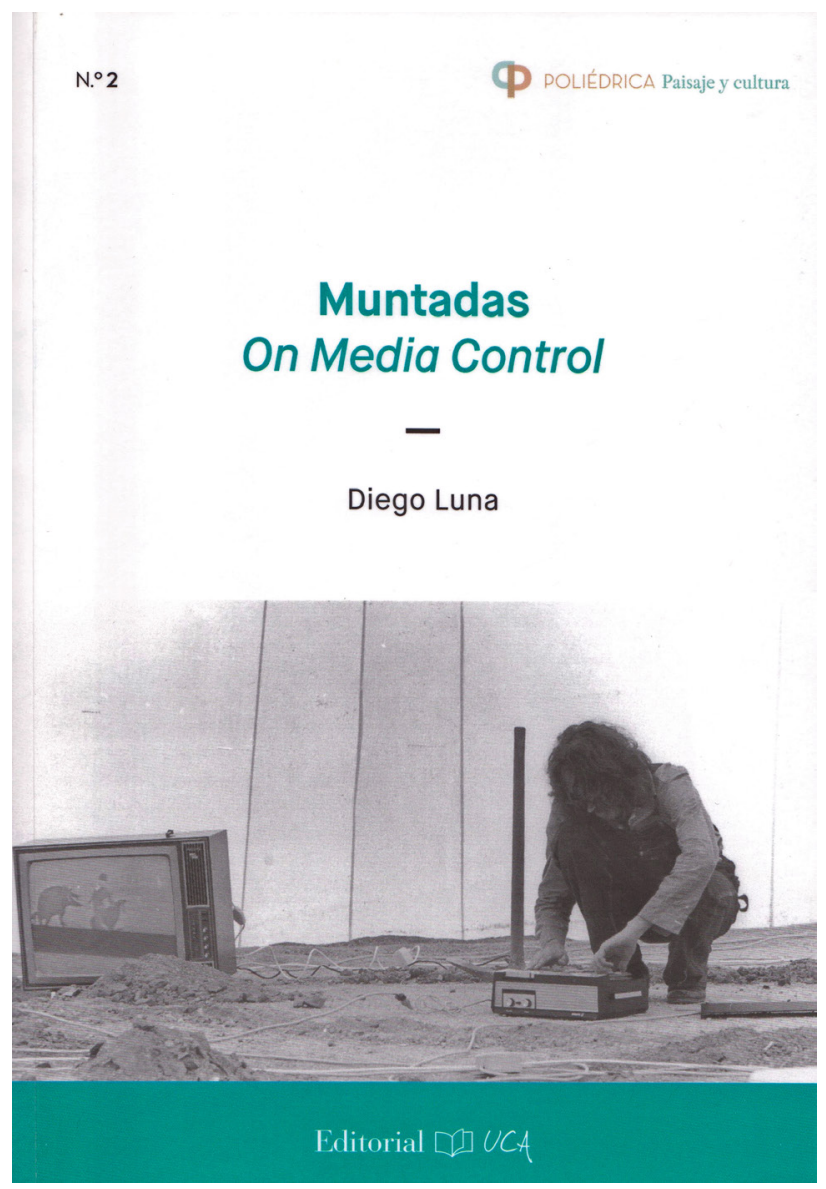

Decía John Szarkowski que las imágenes nuevas derivan en primer lugar de imágenes pasadas. Lo que un artista pone de nuevo en su obra -que es especial para su vida o su mirada- sirve para desafiar y revisar su tradición tal y como le ha venido dada. Leyendo la obra de Diego Luna Delgado, nos damos cuenta de que Antoni Muntadas no se preocupa de revisar su tradición. Tampoco la desafía. Directamente, el artista catalán lo que hace es transgredir los límites de su tiempo y, siendo una persona comprometida con su presente, se anticipará en cierta medida a la vanguardia que vendrá. Si acaso, será la técnica imperante la que ponga cierto límite a la exposición de sus ideas, pero ya desde sus inicios, Muntadas se hizo con una Súper 8 y empezó a utilizar el vídeo para trascender la pintura. Sus años de formación, en la última etapa del franquismo, le harán recorrer ciudades como Barcelona y París, pero será al pasar por instituciones como el Pratt Graphic Center de Nueva York y, el Center for Advanced Visual Studies del Massachusetts Institute of Technology (MIT), donde conseguirá convertirse en uno de los grandes artistas que orbitarán en torno a los Mass Media.

El libro escrito por Diego Luna, Muntadas On Media Control, aborda la trayectoria vital del artista catalán, pero va mucho más allá de ser una mera biografía. En sus páginas encontraremos sobre todo un análisis discursivo con varias dimensiones a tener en cuenta, y dichas dimensiones (tales como la filosófica, la historiográfica, la política o, la socioeconómica, entre otras) se intercalarán para una mejor comprensión de la obra de arte muntadiana y su tiempo. Sobre los proyectos de Antoni Muntadas, nos advierte Luna, hay mucha bibliografía, aparte de los ensayos del propio artista y lo escrito en los catálogos de las exposiciones numerosas que se han llevado a cabo. Pero será bajo esta perspectiva multidimensional, donde seremos conscientes del grado de trascendencia que el autor le transfiere a su discurso.

El índice se divide en cuatro capítulos, correspondiéndose el último de ellos con las conclusiones. No obstante, en la introducción, llamada Foucault after Muntadas, se pone el foco en el carácter filosófico-conceptual, algo que es un acierto porque al acceder a la psique del artista, vamos a ver quién es el sujeto de estudio antes de explorar su trayectoria. El interés primordial de Muntadas está en la búsqueda de un compromiso político por la democratización de los media. Y por eso, su obra, basada en una metodología procesual, se enriquece de tres niveles de intencionalidad superpuesta: la gramática de la obra, su potencial político y la función que en ella desempeña el sujeto. Así pues, la introducción, entendida como una prolongación necesaria de lo que Foucault preconizara años antes, atiende al Paisaje de los Mass 
Media, título de una de las obras de Muntadas, y escapando definitivamente de la visión de Víctor Hugo que, entendía que «La prensa es la inmensa y santa locomotora del progreso», se busca ahora, desde sus orígenes, rastrear el empleo de las «microfísicas del poder» que, antes que el arte, crearon el Media Landscape (paisaje mediático), término acuñado por el propio Muntadas para referirse a la configuración social. De hecho, dentro de los idearios del artista, otro elemento a tener en cuenta sería la «subjetividad crítica», pues este será el dispositivo de subversión contra las mecánicas de control social que emplean los medios, entendiéndose siempre que, aunque se intenta ser crítico, ningún punto de vista crítico de ningún individuo puede ser objetivo.

El texto de Diego Luna, como se puede observar, aporta por tanto un discurso muy bien estructurado, y aunque el capítulo 1, que se dispone como una breve introducción biográfica, no ofrece demasiada extensión al conjunto de la obra, es interesante en cuanto al itinerario curricular que muestra de Antoni Muntadas, siendo de especial interés su etapa estadounidense, donde completaría su formación como artista en el MIT; desempeñando durante más de dos décadas, entre 1977 y 1998, tareas como becario investigador y como conductor del seminario New Medial Media Culture. En el segundo capítulo, sin embargo, una vez realizadas las presentaciones, o lo que es lo mismo, una vez conocemos el quién, el dónde y el cuándo, se nos propone una aproximación al cómo. Este capítulo 2 se llama En torno al Media Art, y por supuesto, representa una interpelación o diálogo sobre los modos de hacer arte. Leeremos pues, que Muntadas propone un despliegue de formatos: folletos, fotografías, carteles, periódicos, pancartas, televisiones, textos, CDs, cajas de luz, sonidos, fragmentos arquitectónicos, proyecciones de vídeo monocanal y multicanal, instalaciones multimedia, Internet y un largo etcétera, y esto es precisamente lo que García Canclini denominó como «transculturaciones». No obstante, más allá del propio material empleado, Muntadas habla sobre las estrategias de deconstrucción, y define que las técnicas (la fotografía, la T.V., Internet, etc.) en cuanto a técnicas son dispositivos, elementos fríos, por lo que la idea de proyecto se verá lograda según el procedimiento que "caliente» estos elementos, y si el producto final alcanza el reconocimiento de arte, entonces, hay que redefinir la noción clásica de obra artística. Finalmente, los proyectos de Muntadas se caracterizan por un fuerte compromiso político, y en este sentido, hay que dirigir la mirada hacia el site-specific y el time-specific, cuestiones también de suma importancia, pues estos términos se refieren a los lugares donde va a desarrollarse la obra de arte y su tiempo, por lo que obtendremos obras políticas y comprometidas, pero también obras del momento concreto, en definitiva, trabajos de un fuerte impacto social que, como decíamos, definirán el concepto clave que el artista acuñara en los años 70: el Media Landscape.

El capítulo 3 es aquel que mejor invita a la reflexión. En estas páginas es donde Diego Luna Delgado logra el clímax de su discurso. Comparte nombre con el título general de la obra: On Media Control, y a su vez, esta parte se divide en cuatro subcapítulos, que serán llamados de la siguiente manera: Media Landscape; lógica del neoliberalismo; síntomas de la globalización y, censura y vigilancia. Ya de por sí, desde la propia concepción de estos títulos o espacios discursivos, uno se predispone para la introspección artística. De hecho, al inicio de esta reseña hablábamos del carácter multidimensional del libro, y si en las páginas anteriores ha predominado un enfoque artístico-filosófico, es aquí donde estas dimensiones se verán desplegadas para un mejor entendimiento del artista, su obra, y el tiempo en el que se inscribe el trabajo que realiza. Por supuesto, se analizan las obras de arte que Antoni Muntadas desarrolla a lo largo de los años, pero más allá de obtener un compendio cronológico de las mismas, esa óptica multidimensional a la que hacemos referencia logra una máxima comprensión de cada una de ellas. Por ejemplo, la obra Confrontations, de 1974, se estaba realizando en mitad del caso Watergate, por lo que va a incluir retazos de una entrevista que se le realizó a Richard Nixon tras el escándalo. La obtención de una vertiente historiográfica queda aquí visibilizada, pero también la huella de una tensión política, y todo permanecerá inserto dentro de una obra de arte que invita a la reflexión social. El Media Landscape en su máxima expresión, el «Arte Vida», que también se convierte en lema de Muntadas por este tiempo. Toda una sucesión de dimensiones varias que enriquecen la óptica del discurso, y que no se queda en una mera recopilación cronológica de obras de arte explicadas o conceptualizadas. De especial interés será la parte en que Antoni Muntadas trabaja en Cadaqués, como una prolongación lógica del aura artística que nacería décadas antes en aquel mismo lugar gracias 
al genio de Dalí o García Lorca. Su obra Cadaqués-Canal Local, será un gran reflejo de ese tiempo, y haciendo grabaciones de vídeo, lo que mostrará en dicha obra son entrevistas a gente normal. Se reflexiona sobre el turismo de masas, en una localidad catalana que tiene normalmente 1.300 habitantes, pero que vería multiplicada por diez esa cifra en verano.

Así pues, a lo largo del capítulo 3, obra a obra, etapa tras etapa, obtendremos la trayectoria vital del artista catalán, y veremos también cómo, a lo largo de la misma, se implica en una multitud de proyectos, como aquellos pertenecientes al Grup de Treball o, con esas propuestas expositivas que llevará a cabo por todo el mundo. Por lo tanto, este libro no deja de ser una gran biografía sin ser una biografía, es mucho más que eso, en realidad es una visión de una época inacabada, la del siglo XX y su continuación hasta el presente; y esa visión será obtenida a través de la mirada de Antoni Muntadas. Esa mirada, y siempre a través de la prosa de Luna, aborda además aspectos socioeconómicos de trascendencia, tales como el neoliberalismo, la globalización (atiéndase al término glocal), o las implicaciones del poder en aprovechamiento de los medios de comunicación. Discursos de vigente actualidad y que, ya se ha advertido anteriormente, llegan hasta el presente, por lo que tienen su contrarréplica a través de una obra artística muntadiana.

El trabajo de Diego Luna Delgado es una gran investigación, no pretende ser más que eso, la plasmación de un esfuerzo que se advierte productivo, y aunque las conclusiones son breves, como epílogo ofrecen un gran colofón al conjunto del discurso abordado. Además, el libro también incluye unos apéndices de lo más interesantes, pues más allá de brindar una serie de documentos secundarios, se aportan dos entrevistas que el autor le hace a Antoni Muntadas mientras recopilaba información para su proyecto. Se obtiene así un documento novedoso, inédito y que muestra de manera íntima la voz del propio artista. Finalmente, la obra también aporta unas imágenes en blanco y negro, algunas de las obras de Muntadas, pero si este libro merece una crítica, es la escasez de fotografías que puedan enseñar, visualmente, la composición de dichas obras. Un número mayor de estas fotografías, y una intercalación de las mismas dentro de las páginas que las referencia, hubiesen ofrecido un resultado mejor a una obra que se entiende sobresaliente.

\section{M. ${ }^{a}$ Antonia Blanco Arroyo} Universidad de Sevilla 